NBER WORKING PAPER SERIES

COMPLEMENTARITIES AND COMOVEMENTS

John Shea

Working Paper 5305

NATIONAL BUREAU OF ECONOMIC RESEARCH

1050 Massachusetts Avenue

Cambridge, MA 02138

October 1995

The author thanks Eric Bartelsman for help obtaining data from the Penn-SRI-Census Productivity Database, and Mico Loretan and Mike Lettau for help obtaining County Business Patterns data. I also thank Julio Rotemberg, James Kahn, Ken West, Steve Durlauf, Russ Cooper, Paul Beaudry, Gregory Chow, Ben Bernanke, Angus Deaton, John Leahy, and seminar participants at Wisconsin, Columbia, Wharton, Boston University, Princeton, and the NBER Summer Institute for helpful discussions. All errors are mine. Research support from the National Science Foundation is acknowledged. This paper is part of NBER's research program in Monetary Economics. Any opinions expressed are those of the author and not those of the National Bureau of Economic Research.

() 1995 by John Shea. All rights reserved. Short sections of text, not to exceed two paragraphs, may be quoted without explicit permission provided that full credit, including $\odot$ notice, is given to the source. 


\title{
COMPLEMENTARITIES AND COMOVEMENTS
}

\begin{abstract}
Short-run interindustry comovement may be due either to common shocks or to complementarities that propagate shocks across sectors. This paper assesses the importance of input-output linkages, aggregate activity spillovers, and local activity spillovers to comovement in postwar US manufacturing. I find that input-output linkages and local activity spillovers are important to comovement, while aggregate activity spillovers are not important. I find that complementarities are important to aggregate volatility, even after I remove observable aggregate shocks from the data. Local spillovers are particularly important, explaining between 15 and 36 percent of manufacturing employment volatility.
\end{abstract}

John Shea

Department of Economics

University of Wisconsin 1180 Observatory Drive Madison, WI 53706

and NBER 


\section{INTRODUCTION}

Positive comovement between different sectors of the economy is a salient feature of business cycles. Over the period 1959-1986, for instance, the average pairwise correlation of annual employment growth for the 126 three-digit US manufacturing industries listed in the Appendix is 0.341. For gross output and value added, the corresponding figures over 1960-1986 are 0.284 and 0.228. Similar evidence is presented in Long and Plosser (1987), Murphy, Shleifer and Vishny (1989 a), and Cooper and Haltiwanger (1990).

Interindustry comovement is essential to aggregate output and employment volatility. To see this, suppose we approximate the growth rate of some aggregate activity measure, denoted $q$, as a weighted average of disaggregated industry growth rates:

$$
q_{t} \cong \sum_{i=1}^{M} \operatorname{SHARE}_{i} q_{i t},
$$

where $M$ is the number of sectors and SHARE $_{i}$ equals sector i's steady-state share of aggregate activity. Then the variance of $q$ is approximately

$$
\text { SHARE * } \Psi * \text { SHARE' }^{\prime}
$$

where SHARE is a 1 -by- $M$ vector of industry shares and $\Psi$ is the $M-b y-M$ variance-covariance matrix of disaggregated industry activity.

From (2), one can decompose the approximate variance of $q$ into a term due to the diagonal elements of $\Psi$, and a "comovement" term due to the off-diagonal elements of $\Psi$. Table 1 presents this decomposition for manufacturing employment, gross output and value added growth, using 
annual data over 1959-86 for employment and over 1960-86 for output and value added. The matrix $\Psi$ and the vector SHARE are estimated using 126 three-digit manufacturing industries; the data are described in the appendix.

The results suggest that most aggregate volatility is due to interindustry comovement. For instance, the actual standard deviation of annual manufacturing employment growth over the sample period is 4.31 percent. The approximate standard deviation implied by (2) is 4.42 percent. The standard deviation implied by the diagonal elements of $\Psi$ is just 0.99 percent, while the standard deviation implied by the off-diagonal elements of $\Psi$ is 4.31 percent; comovement thus accounts for almost 95 percent of the variance of manufacturing employment. Qualitatively similar results hold for output and value added.

In principle, interindustry comovement could be due entirely to the direct effects of common shocks. For instance, monetary policy may iirectly affect the demand for all durable goods. However, comovement may also be caused by complementarities that propagate shocks across sectors. For instance, monetary policy may generate comovement between cars and steel not because money affects steel directly, but because money affects cars and because shocks to cars are transmitted to steel. Recent research has suggested several potential sources of interindustry linkage, including the input-output table (Long and Plosser (1983)), trading externalities (Diamond (1982)), and aggregate demand spillovers (Murphy, Shleifer and Vishny $(1989$ b)). Some of these linkages, such as input-output, are consistent with frictionless models; others inherently rely on frictions such as imperfect competition or externalities. ${ }^{1}$ The common implication of such theories is that the interindustry pattern of 
comovement depends on the interindustry pattern of linkage. Complementarities do not merely imply that A should comove with B; they imply that the amount of comovement between $A$ and $B$ should depend on the strength of the linkages between $A$ and $B$.

This paper assesses the importance of complementarities for short-run comovement. Using postwar US data for disaggregated industries, I examine the relationship between the observed pattern of comovement and observable measures of complementarity suggested by three simple models. In Model One, shocks are propagated by factor demand linkages. The model implies that the effect of a shock to industry $A$ on industry $B$ depends on the strength of upstream and downstream linkages between $A$ and $B$. In Model Two, shocks are propagated by an aggregate spillover, as in Baxter and King (1991); increases in aggregate output raise optimal output in each industry. The model implies that the effect of a shock to $A$ on $B$ depends on A's size: shocks to large industries have a larger aggregate impact than shocks to small industries, and are thus transmitted more strongly to other sectors. In Model Three, shocks are propagated by a local spillover; increases in overall city output raise optimal output in each local industry. The model implies that at the national level, the effect of a shock to industry $A$ on industry $B$ depends both on $A$ 's size and on whether $A$ and $B$ cluster in the same cities. Industries with a strong "spatial correlation" should exhibit strong temporal comovement.

The models imply that industry fluctuations result from the propagation of shocks through a matrix whose elements depend on observable measures of potential complementarity and on parameters governing the strength of different linkage mechanisms. Given sufficient restrictions on the covariance matrix of underlying shocks, I can estimate the 
complementarity parameters using data on disaggregated industry fluctuations. My empirical work examines the pattern of comovement among 126 disaggregated US manufacturing industries, using annual data covering 1958-1986. I assess the importance of complementarities in two ways: first, I examine whether the complementarity parameters are statistically significant and of the correct sign; second, I measure the contributions of complementarities to aggregrate volatility.

The rest of this paper proceeds as follows. Section II outlines the three models. Section III describes data sources and presents empirical results. Section IV compares my work to previous literature, and Section $V$ concludes. My main results are as follows. I find that input-output linkages are important to short-run comovement, with significant linkages running both from downstream users to upstream suppliers and vice-versa. I find little support for aggregate activity spillovers. However, I find strong support for local activity spillovers; even after controlling for input-output linkages, industries clustered in the same cities tend to comove over the business cycle. I find that complementarities are important to aggregate volatility, even after removing observable aggregate shocks from the data. Local spillovers are especially important; for instance, I estimate that local spillovers are responsible for between 15 and 36 percent of employment volatility in manufacturing, depending on my treatment of aggregate shocks.

\section{I. THREE MODELS OF INTERINDUSTRY COMPLEMENTARITY}

This section presents three models of interindustry linkage. The models are simple, for the sake of analytic and empirical tractability. Nevertheless, I believe the models capture the essential implications of 
their respective linkage mechanisms for the pattern of interindustry comovement, and that the models' qualitative predictions would thus remain true in richer models; exceptions are duly noted.

\section{Model One: Factor Demand Linkages}

This subsection presents a multisectoral general equilibrium model in which shocks are propagated by input-output linkages, as in Long and Plosser (1983). There is a representative agent with preferences

$$
U=\sum_{i=1}^{N} \alpha_{i} \log \left(C_{i}\right)-L ; \quad \alpha_{i}=a_{i} \exp \left(d_{i}\right) ; \sum_{i=1}^{N} a_{i}=1 .
$$

Utility depends on consumption $\mathrm{C}_{\mathrm{i}}$ of $\mathrm{N}$ goods, and on hours worked $\mathrm{L}$. The goods have stochastic preference weights $\alpha_{i}$. Some goods receive more weight than others on average; this is reflected in the fixed $a_{i}$ parameters. The $d_{i}$ are mean-zero taste (demand) shocks.

Each good is produced using both labor and intermediate inputs, where each of the $\mathrm{N}$ goods is potentially used as an input by every other good:

$$
Q_{i}=\lambda_{i} *\left[\prod_{k=1}^{N}\left(x_{k i}\right)^{\beta} k_{i}\right] * L_{i}^{\gamma} ; \quad \gamma_{i}+\sum_{k=1}^{N} \beta_{k i}=1
$$

Here, $Q_{i}$ is output of good $i$; $X_{k i}$ represents the amount of $k$ used as an input for $i$; and

$$
\lambda_{i}=\exp \left(s_{i}\right)
$$

where the $s_{i}$ are mean-zero technology (supply) shocks. Finally, market clearing requires

$$
Q_{i}=\sum_{k=1}^{N} X_{i k}+C_{i} ; \quad L=\sum_{i=1}^{N} L_{i} .
$$

A log-linear approximation to the competitive equilibrium yields 


$$
q_{i}=k_{i}+\sum_{k=1}^{N} \operatorname{CosT}{ }_{i k} s_{k}+\sum_{k=1}^{N} D_{i k} d_{k}
$$

where $\mathrm{K}_{\mathrm{i}}$ is a constant. According to (7), fluctuations in industry $\mathrm{i}$ depend on technology and taste shocks in every industry. The effect of the technology shock $s_{k}$ on $q_{i}$ depends on $\operatorname{COST}_{i k}$, equal to the ultimate dollar requirement of good $k$ per dollar sold of good $i$, incorporating direct and indirect linkages. For instance, $\operatorname{COST}_{i k}$ could be high because $\mathrm{i}$ uses $\mathrm{k}$ as an input, or because $\mathrm{i}$ uses $\mathrm{h}$ while $\mathrm{h}$ uses $\mathrm{k}$, and so on. The effect of the taste shock $d_{k}$ on $q_{i}$, meanwhile, depends on $D E M_{i k}$, equal to the steady-state share of demand for i ultimately embodied in final purchases of $k$. DEM and COST are in turn functions of the taste and production parameters; details are provided in the appendix.

Notice that this model is oversimplified in that supply and demand shocks propagate in only one direction each. Technology shocks to industry A propagate downstream, affecting costs in sectcrs using $A$ as an input, but do not affect upstream sectors supplying inputs to $A$. This is because utility and production functions are Cobb-Douglas. In general, (neutral) technology shocks have two competing effects on upstream demand: they reduce the amount of input needed to produce any given level of industry output, but they also raise industry output. Under Cobb-Douglas, these two effects cancel exactly; under alternative specifications, technology shocks could have upstream effects. Conversely, in this model taste shocks to industry A shift upstream demand curves, but do not affect downstream sectors using $A$ as an input. This is because supply curves are flat. If A's supply curve sloped up, then favorable taste shocks would raise $A^{\prime}$ s price, raising costs to downstream sectors. On the other hand, if A's supply curve sloped down, then taste shocks would lower costs to 
downstream sectors.

In the empirical work below, I assess the roles of upstream versus downstream linkages for comovement, using input-output matrices modelled on DEM and COST. While it is sometimes useful to refer to upstream propagation of shocks from users to suppliers as a "demand-side linkage", and downstream propagation from suppliers to users as a "supply-side linkage", the reader should keep in mind that the empirical results will reveal only the direction in which shocks propagate; the results will not in general reveal whether the fundamental shocks driving the economy are demand or supply shocks.

Model Two: Aggregate Activity Spillovers

This subsection presents a model in which shocks are propagated by an aggregate activity spillover. The representative agent's utility is

$$
U=\sum_{i=1}^{N} \alpha_{i} \log \left(Q_{i}\right)-L \quad ; \sum_{i=1}^{N} \alpha_{i}=1
$$

As in Model One, utility depends on consumption $\mathrm{Q}_{\mathrm{i}}$ of $\mathrm{N}$ final goods, and on hours worked L. The goods have nonstochastic preference weights; sectors with a high $\alpha$ are larger on average than sectors with low $\alpha$.

Final goods are produced according to

$$
Q_{i}=\lambda_{i} L_{i}\left(Q_{A}\right)^{\beta} ; \lambda_{i}=\exp \left(s_{i}\right)
$$

where

$$
Q_{A}=\sum_{i=1}^{N} Q_{i} ; L=\sum_{i=1}^{N} L_{i}
$$

Output of good $i$ depends on labor, on productivity $\lambda_{i}$, and on aggregate activity $Q_{A}$, where $\beta$ lies in the interval 10,1$)$. Assume that $Q_{A}$ 
is an externality; firms make decisions taking $Q_{A}$ as given. Then a log-linear approximation to the competitive equilibrium yields

$$
q_{i}=\log \left(\alpha_{i}\right)+s_{i}+\mu \sum_{z=1}^{N} \alpha_{z} s_{z}
$$

where $\mu$ equals $(\beta / 1-\beta)$. From (11), fluctuations in industry i depend on i's technology shock and on the aggregate activity index, which is a size-weighted average of all technology shocks. For simplicity, I have assumed that the aggregate spillover is an external economy of scale, as in Baxter and King (1991). However, an equation similar to (11) would presumably hold under other types of aggregate spillovers; the key feature of (11) is that shocks to large sectors have larger aggregate impacts, and thus larger effects on other sectors, than shocks to small sectors. ${ }^{2}$ Notice that the effect of size on comovement in this model does not merely follow from the fact that large industries comprise a higher fraction of aggregate output than small industries. While it is true that the effect of industry shocks on aggregate output would trivially tend to increase with size in virtually any model, the effect of industry shocks on other industries increases with size only if aggregate spillovers are present. ${ }^{3}$

Model Three: Local Activity Spillovers

This subsection presents a model in which goods are produced in a large number of spatially distinct locations. Shocks are propagated by a symmetric local spillover, in which productivity in a particular industry-city depends on overall city output. The chief implication of the model is that the interindustry patterns of temporal comovement and spatial location should be similar.

The representative agent's utility at time $t$ is 


$$
U_{t}=\sum_{i=1}^{N} C_{i t}-L_{t}
$$

Utility depends on the consumption $\mathrm{C}_{\text {it }}$ of $\mathrm{N}$ final goods, and on hours worked. Each final good, in turn, can be produced in a large number $M$ of cities. In order to avoid complete concentration of industries in one city, I assume that different cities produce differentiated versions of each final good, which are imperfect substitutes in utility. Thus,

$$
C_{i t}=\sum_{j=1}^{M} \log \left(Q_{i j t}\right),
$$

where $Q_{i j t}$ is production of good $i$ in city $j$ at time $t$, given by

$$
Q_{i j t}=u_{i j t} * L_{i j t} *\left(Q_{j t}\right)^{\beta},
$$

where

$$
u_{i j t}=\exp \left(s_{i t}\right) * \exp \left(w_{i j}\right)
$$

and

$$
Q_{j t}=\sum_{i=1}^{N} Q_{i j t} .
$$

Production in an industry-city depends on labor; on the overall level of city activity $Q_{j t}$; and on the productivity shifter $u_{i j t}$, which in turn depends on two terms: $s_{i t}$, which varies over industries and time but not cities; and $w_{i j}$, which varies across industry-cities but not time. One can think of $s$ as an industry-specific technology shock and $w$ as a Ricardian parameter reflecting long-run attributes that give particular cities a comparative advantage in hosting certain industries.

Assume that agents regard local activity spillovers as an externality. Let $Q_{i t}$ denote industry i's total output at time $t$, equal to 
the sum of $Q_{i j t}$ over $M$ cities. Then a log-linear approximation to this economy's competitive equilibrium yields

$$
q_{i t}=k_{i}+s_{i t}+\mu \sum_{k=1}^{N} C I T Y_{i k} s_{k t},
$$

where the K's are constants, $\mu$ equals $(\beta / 1-\beta)$, and

$$
\text { CITY }_{i k}=\sum_{j=1}^{M} \text { SHARE }_{j i} * \operatorname{SHARE}_{k j} \text {, }
$$

where SHARE $_{j i}$ equals city j's steady-state share of industry i's activity, and where $\operatorname{SHARE}_{k j}$ equals industry k's steady-state share of city j's activity; SHARE1 and SHARE2 in turn depend on the $w$ parameters.

According to (17), fluctuations in industry i depend on technology shocks in all industries. The effect of a shock to industry $k$ on industry

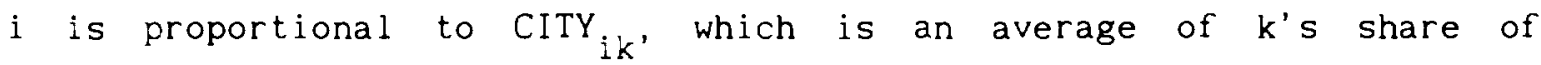
steady-state activity in the M cities, weighted according to each city's steady-state share of i's activity. CITY ${ }_{i k}$ thus measures the extent to which $i$ is concentrated in cities where $k$ is important. Intuitively, if CITY $_{i k}$ is large, then shocks to $k$ have a large impact on activity in cities where $i$ is clustered, and therefore propagate to $i$.

Notice that this model predicts that industries that cluster together in space should also comove through time. From (17), comovement between i and $k$ increases in CITY ${ }_{i k}$, which in turn increases in $k^{\prime} s$ size and in the degree to which $i$ and $k$ cluster in the same cities. The predictions of this model are thus at odds with a Marshallian "labor market pooling" story, in which industries with negatively correlated fluctations optimally cluster together to stabilize local labor demand. ${ }^{4}$

I must point out that symmetric local spillovers are not the only mechanism that could generate a correspondance between the interindustry 
patterns of spatial and temporal comovement. For instance, if city-specific shocks such as weather or taxes are important to fluctuations, then industries clustered in the same cities will tend to comove over time by virtue of experiencing a similar mix of local shocks. Alternatively, there may be asymmetric local spillovers, in which the degree of synergy varies across industry pairs; in this case, pairs with particularly strong linkages will comove over time and will optimally cluster together in space to maximize the synergy. Thus, while I frame the empirical findings below as evidence for symmetric local spillovers, one could also interpret the results as evidence for asymmetric spillovers or local shocks. These stories are difficult to distinguish using national data alone. However, in Shea (1995), I show that the three stories have sharply different implications for the pattern of interindustry comovement within cities, and can thus be distinguished using data on fluctuations at the city-industry level.

\section{EMPIRICAL EVIDENCE}

The models presented above imply that comovement results from the propagation of industry shocks through complementarities. This section presents empirical evidence on complementarities. I first describe my empirical framework. I assume that fluctuations obey

$$
\mathrm{q}_{\mathrm{t}}=\mu+A * \varepsilon_{\mathrm{t}},
$$

where $q_{t}$ is an observable $\mathrm{N}$-by-1 vector of industry fluctuations at time $t ; \mu$ is an $\mathrm{N}$-by-1 vector of constants; $\varepsilon_{t}$ is a vector of mean-zero industry-level shocks, with covariance matrix $\Omega$; and $A$ is an $\mathrm{N}$-by-N matrix governing how shocks are propagated across sectors. The models outlined 
in Section I suggest that A depends on observable measures of interindustry linkage and on parameters governing the strength of different propagation mechanisms. I specify A as follows:

$$
A=\beta_{1} * \operatorname{COST}+\beta_{2} * \mathrm{DEM}+\beta_{3} * \mathrm{SIZE}+\beta_{4} * \text { CITY. }
$$

Here, COST is an $N$-by-N matrix whose $[i, k]$ element equals the ultimate dollar requirement of good $\mathrm{k}$ per dollar sold of good i; DEM is a matrix whose $[i, k]$ element equals the share of demand for i ultimately embodied in final purchases of $k$; SIZE is a matrix whose $[i, k]$ element is proportional to k's size; and CITY is a matrix whose $[\mathrm{i}, \mathrm{k}]$ element equals a weighted average of k's steady-state share of activity over a group of cities, weighted by each city's steady-state share of i's activity. From Section II, COST represents downstream propagation of shocks, from suppliers to users, while DEM represents upstream propagation of shocks, from users to suppliers; SIZE represents aggregate activity spillovers, while CITY represents local spillovers. COST and DEM are meausured using 1977 US input-output data; SIZE is measured using industries' long-run average share of nominal manufacturing value added; and CITY is measured using 1977 disaggregated employment data for 273 cities. ${ }^{5}$ Details on data construction are provided in the appendix.

I estimate (19)-(20) using annual data from 1958-1986 on 126 US three-digit manufacturing industries. I experiment with three measures of q: the growth rate of employment, the growth rate of real gross output, and the growth rate of real value added. These series are constructed using the Penn-Census-SRI Productivity Database used in Bartlesman, Caballero and Lyons (1994); details are provided in the appendix. 
Ident if ication and Estimation

My objective is to use the pattern of interindustry comovement to identify the $\beta$ parameters, along with the elements of the shock covariance matrix $\Omega$. However, I cannot from (19)-(20) estimate both the $\beta^{\prime} s$ and an unrestricted $\Omega$ matrix. My identifying assumption in this paper is that industry shocks consist of two orthogonal components: an unobserved industry-specific component, assumed orthogonal across industries, and a component driven by observable aggregate disturbances. Specifically, I assume that

$$
\varepsilon_{t}=v_{t}+F * a_{t}
$$

Here, $v_{t}$ is an $\mathrm{N}$-by-1 vector of industry shocks, with diagonal covariance matrix $\Sigma ; a_{t}$ is a P-by-1 vector of observable aggregate shocks orthogonal to $v_{t}$; and $F$ is an $N$-by-P matrix of factor loadings, indexing each industry's sensitivity to aggregate shocks. I assume that a consists of two elements: the growth rate of the real Producer Price Index for fuels and power (OIL) and the spread between the commercial paper and Treasury-Bill interest rates (SPREAD), intended to proxy for monetary policy. ${ }^{6}$ Under these assumptions, I can rewrite (19) as

$$
q_{t}=\mu+G * a_{t}+A * v_{t} \text {, }
$$

where

$$
G=A * F \text {. }
$$

In addition to these identifying restrictions, I must choose a normalization; as currently specified, the absolute levels of $\beta$ and $\Omega$ are not separately identified. One possible normalization would be to set $\beta_{1}$ 
and/or $\beta_{2}=1$; this is unappealing because it imposes a restriction that either upstream or downstream input-output linkages must be important to comovement. I instead normalize the own effect of an industry shock to one, and let $\beta_{1}$ through $\beta_{4}$ govern only the cross-industry effects of shocks. In other words, I assume

$$
A=I D+\beta_{1} * \operatorname{COST}+\beta_{2} * \mathrm{DEM}+\beta_{3} * \operatorname{SIZE}+\beta_{4} * \text { CITY, }
$$

where ID is an $\mathrm{N}-\mathrm{by}-\mathrm{N}$ identity matrix and the diagonals of COST, DEM, SIZE and CITY are set to zero.

I estimate the model using a two-step procedure. First, I estimate $\mu$ and $G$ by running industry-by-industry OLS regressions of $\mathrm{q}_{t}$ on a constant, OIL and SPREAD; these regressions fit best when I lag OIL and SPREAD one year. ${ }^{7}$ These estimates are consistent under the assumption that $a_{t}$ is orthogonal to $v_{t} \cdot{ }^{8}$ I then use the residuals from these regressions to estimate $\beta$ and $\Sigma$ using Gaussian maximum likelihood. Details on the log likelihood function and its gradient are given in the appendix. Given estimates of $G$ and $\beta$, I can use (23) to back out estimates of the factor loading matrix $F$, which allows me to distinguish the direct effects of aggregate shocks on comovement from the indirect effects resulting from the propagation of aggregate shocks through complementarities. Of course, this decomposition depends on the assumption that aggregate and industry-specific shocks are propagated through the same matrix A.

Before proceeding to the results, I must must acknowledge two important gaps between the models outlined in Section II and the empirical framework described above. First, while Section II consists of three separate models, I estimate a single system which nests all three models' implications. Allowing for all three linkages simultaneously is essential 
for proper inference; for instance, if I tested Model Two without controlling for input-output linkages, I might find a positive association between industry size and comovement even if aggregate spillovers did not exist, because large industries have stronger input-output links to other sectors than small industries. Unfortunately, nesting the three models limits the structural interpretability of the estimates. For instance, the estimated coefficients on SIZE and CITY can be used to test the null that aggregate and local spillovers do not exist, but cannot be used to infer the aggregate and local spillover parameters in Models Two and Three. Ideally, Section II would consist of a single model nesting all three linkages, so that the empirical estimates would have unambiguous structural interpretations. Unfortunately, I have been unable to find a tractable model incorporating all three linkages.

Second, while Model One shows that demand and supply shocks may have different propagation mechanisms, the empirical work assumes that all shocks propagate in the same way. Attempts to estimate models allowing for both supply and demand shocks proved unsuccesful, although perhaps future work could have more success by incorporating price data. As mentioned above, the empirical work thus cannot answer the question of whether supply or demand shocks are more important to business cycles; the estimates reveal only the relative importance of upstream versus downstream propagation of shocks.

Estimates of $\beta$

Table 2 presents estimates of $\beta$ for the three measures of industry activity. Estimates of $G$ and $\Sigma$ are omitted to save space, but are available from the author. Standard errors are in parentheses and are estimated by numerical computation of the Hessian at the maximum 
likelihood estimates.

Results are as follows. First, input-output linkages are significant sources of short-run comovement. The coefficients on DEM and COST are positive and significant in all cases, suggesting that shocks propagate both upstream (from users to suppliers) and downstream (from suppliers to users). Second, aggregate activity spillovers receive little support; the coefficient on SIZE is positive in all cases, but statistically insignificant. Third, local activity spillovers receive strong support; the coefficient on CITY is positive and highly significant in all specifications. Finally, the results for employment and output are similar to each other, but different from the results for value added, which show smaller coefficients on DEM and COST and larger coefficients on SIZE and CITY. Since measuring value added requires both more information and more assumptions about the production function than measuring employment or output, value added is likely to contain more measurement error than employment or output; therefore, the employment and output results should perhaps carry more weight than the value added results.

Table 3 presents statistics describing the fit of the models. For each activity measure, the column "Implied Volatility" presents the standard deviation of manufacturing activity implied by the formula

$$
\operatorname{Var}(\mathrm{q})=\text { SHARE}^{\prime *} * * \text { SHARE. }
$$

Here, SHARE is a 126-by-1 vector of steady-state industry activity shares, estimated as described in the appendix. In rows labelled "Data", $\Psi$ is set equal to the covariance matrix of the original data; in rows labelled "Residuals", $\Psi$ is the covariance matrix of the residuals from projecting the data on aggregate shocks. In the remaining rows, $\Psi$ equals the fitted covariance matrix, either including or excluding the effects of 
aggregate shocks. In the former case, $\Psi$ equals $\hat{A} * \hat{\Sigma} * \hat{A}^{\prime}$ plus $\hat{G} * \hat{\phi} *$ $\hat{G}^{\prime}$, where $\hat{\phi}$ is the estimated covariance matrix of aggregate shocks; in the latter case, $\Psi$ equals $\hat{A} * \hat{\Sigma} * \hat{A}^{\prime}$. The last three columns, meanwhile, report statistics for the pairwise correlations implied by the data and the empirical estimates; the fourth and fifth columns show the mean and standard deviation of the pairwise correlations over the 7875 possible pairs of sample industries, while the sixth column presents the correlation between the fitted and observed pairwise correlations. ${ }^{9}$

The results of Table 3 suggest that the fitted model can account for most of the volatility and comovement features of the data. For employment, the fitted model including the effects of aggregate shocks explains 96 percent of the variance and 89 percent of the mean pairwise correlation found in the data; for gross output, the model explains over 100 percent of aggregate variance and 99 percent of average comovement; for value added, the model explains over 100 percent of both aggregate variance and average comovement. Removing aggregate shocks from both the model and the data has little effect on these results. For all three activity measures, the pairwise correlations in the original data themselves exhibit a correlation of around 0.78 with the correlations implied by the fitted model including aggregate shocks; this suggests that the model including aggregate shocks can account for why some pairs of industries comove more strongly than others. The model without aggregate shocks is not as successful at explaining cross-sectional variation in the degree of comovement; the correlation between the residual correlations and the fitted correlations excluding aggregate shocks ranges from 0.286 for employment to 0.386 for gross output. The fitted models tend to understate somewhat the standard deviation of observed pairwise 
correlations, especially when aggregate shocks are excluded; the fitted models thus do not account especially well for the magnitude of variation in the degree of comovement across industry pairs.

Variance Decompositions

While the estimates of the $\beta^{\prime}$ s are interesting, they do not prove that complementarities are economically important. Table 4 assesses economic significance by decomposing the aggregate variance implied by the fitted model into components due to aggregate shocks, input-output linkages, local spillovers, and other factors. The variance decomposition results depend crucially on how one measures the impact of aggregate shocks. The third column measures this impact as $\hat{G}$, the matrix of coefficients from projecting $y$ on aggregate shocks industry-by-industry. This measure assigns to aggregate shocks both their direct effects and the indirect effects resulting from their propagation through complementarities. The final column measures the impact of aggregate shocks as $\hat{F}=\hat{A}^{-1} * \hat{G}$. This measure includes only direct effects, and is based on the assumption that aggregate shocks are propagated by the same complementarities as idiosyncratic shocks. For each activity measure, the first row presents the fraction of fitted variance attributable to aggregate shocks, setting $\Psi$ either to $\hat{G} * \hat{\Phi}^{*} \hat{G}^{\prime}$ (third column) or $\hat{F} * \hat{\Phi} *$ $\hat{F}^{\prime}$ (fourth column). The row "Diagonals" presents the fraction of fitted variance due to idiosyncratic shocks, setting $\Psi$ to $\hat{\Sigma}$. The row COST presents the fraction of volatility due to cost-side linkages; this row is constructed by first defining $\hat{A}_{\text {COST }}=I D+\hat{\beta}_{1} \operatorname{cosT}$ and $\hat{G}_{\operatorname{COST}}=\hat{A}_{\operatorname{COST}} * \hat{F}$, then setting $\Psi$ equal to either $\hat{A}_{\operatorname{COST}} * \hat{\Sigma} * \hat{A}_{\operatorname{COST}}$ (third column), or to $\hat{A}_{\mathrm{COST}} * \hat{\Sigma} * \hat{A}_{\mathrm{COST}}{ }^{\prime}+\hat{\mathrm{G}}_{\mathrm{COST}} * \hat{\Phi}^{*} \hat{\mathrm{G}}_{\mathrm{COST}}$ (fourth column); one can think of 
$\hat{G}_{\operatorname{COST}}$ as an estimate of what the overall impact of aggregate shocks would be if cost linkages were the only complementarity in the economy. The third column of row COST subtracts the variance due to idiosyncratic shocks, while the fourth column subtracts the variance due to idiosyncratic shocks and to the direct impact of aggregate shocks. The rows DEM, SIZE, and CITY are constructed in the same way as COST, while the row "Interactions" reports the fraction of variance due to interactions between COST, DEM, SIZE and CITY.

The results of Table 4 suggest that both aggregate shocks and complementarities are important to aggregate volatility. If we measure the impact of common shocks using $\hat{G}$, then aggregate shocks explain over half of manufacturing employment volatility, 45 percent of output volatility, and almost 40 percent of value added volatility. The importance of aggregate shocks falls substantially, however, if we measure their impact using $\hat{F}$ instead of $\hat{G}$; for each activity measure, the share of volatility attributable to the direct effects of aggregate shocks is less than five percent. This suggests that complementarities play an important role in transmitting oil and monetary shocks across sectors, provided one assumes that aggregate and idiosyncratic shocks are propagated through the same channels. Interestingly, local spillovers appear to be the most economically important complementarity. If we ignore the role of complementarities in propagating common shocks, local spillovers explain between 15 and 19 percent of aggregate volatility, depending on the measure of activity; these figures rise to around 35 percent if we allow local spillovers to propagate aggregate as well as idiosyncratic shocks. Regardless of the treatement of aggregate shocks, then, local spillovers have non-trivial consequences for volatility in manufacturing. 
Input-output linkages are nearly as important as local spillovers for gross output volatility, but are not as important for employment or value added volatility.

\section{COMPARISON WITH PREVIOUS WORK}

In contrast to the large theoretical literature, there is relatively little existing empirical work on complementarities. ${ }^{10}$ There is a literature that analyzes comovements among disaggregated industries using latent factor models; examples include Long and Plosser (1987), Cooper and Haltiwanger (1990) and Norrbin and Schlagenhauf (1990). Papers in this tradition typically focus on questions concerning the economy's underlying shocks, such as the number of common factors or the relative importance of aggregate and sectoral disturbances. In terms of my notation, this literature is thus interested primarily in $\Omega$ rather than $A$. Complementarities are usually assumed to operate only with lags; these papers thus typically decompose fluctuations into predictable and unpredictable componenets, and assume that the unpredictable component depends only on the underlying shocks. Moreover, complementarities are usually not modelled in terms of observable variables. 11

My work differs from this literature in several respects. First, I do not decompose fluctuations into predictable and unpredictable components. This is because I do not agree with the assumption that complementarities operate only with lags; this assumption seems especially unrealistic when applied to annual data. Second, I focus primarily on the structure of interindustry complementarities rather than the structure of common shocks. Finally, I model both complementarities and aggregate shocks in terms of observable variables, rather than relying on 
unobservable common factors or principal components to explain the data.

Bartlesman, Caballero and Lyons (1994) is perhaps the closest antecedant of the present paper. These authors find that a demand-share weighted aggregate of other sectors' activity raises an industry's productivity in the short run, while a cost-share weighted aggregate is unimportant to short-run productivity but important to long-run productivity growth. My work differs from Bartlesman et al in the following ways. First, I estimate a model of the interindustry covariance matrix, rather than a system of production function regressions; my framework is harder to estimate, but is perhaps more readily adaptable to alternative specifications of spillovers or common shocks. Second, I examine output and employment rather than productivity; I believe that productivity data is too clouded by factor utilization to be useful for measuring short-run fluctuations in true productivity. Finally, I analyze a richer set of complementarity measures, including local spillovers.

\section{CONCLUSION}

This paper has investigated the role of complementarities in the short-run propagation of shocks. Using data on disaggregated manufacturing industries in the postwar United States, I find that input-output linkages are important to short-run comovement, with significant links running both from users to upstream suppliers and from suppliers to downstream users. I also find that aggregate activity spillovers are not important to short-run comovement.

The most important finding of this paper is that industries that cluster together in space also tend to comove through time, and that the comovement associated with this correspondance accounts for a large 
fraction of aggregate volatility. In this paper, I interpret this phenomenon as evidence for symmetric local activity spillovers. However, as mentioned in Section II, a link between spatial and temporal correlation could also result from city-specific shocks or asymmetric local spillovers that vary across industry pairs. Distinguishing among these stories using national-level data alone would be difficult, since all three stories have broadly similar implications for interindustry comovement at the national level. In parallel work (Shea (1995)), however, I show that city-specific shocks, symmetric local activity spillovers and asymmetric local spillovers have sharply different implications for the pattern of interindustry comovement within cities. I test these implications using time-series employment data for 387 city-industries taken from seven large US metropolitan areas, and find evidence for both symmetric and asymmetric local spillovers. ${ }^{12}$

There are a number of ways in which this paper could be extended. First, one could examine higher-frequency data and allow shocks to propagate dynamically; for instance, it might be interesting to know how quickly shocks travel through the input-output table, or whether direct linkages are realized more quickly than indirect linkages. Second, one could examine other linkage mechansisms, by adding additional elements to the matrices $A$ or $\Omega$. Third, one could apply this paper's methodology to analyze comovements among other vector time series, such as international outputs or asset prices. With suitable modifications, the framework employed here should be applicable to any problem where one wants to test competing theories of how shocks are propagated across agents, provided theory expresses linkages as a function of observable data and a small number of parameters. 
APPENDIX

Maximum Likelihood Estimation

Let $\tilde{q}$ denote the residuals from projecting industry growth rates on a constant and aggregate shocks. Then from (22), we have

(A. 1)

$$
\tilde{\mathrm{q}}_{\mathrm{t}}=A * v_{t}
$$

where $A$ is given by (24) in the text, and where $\Sigma=\operatorname{Var}(v)$ is diagonal. Assuming that $v$ is Gaussian, the $\log$ likelihood function for $T$ observations on the vector $\tilde{q}_{t}$ is given by

(A.2) $\log L=-(T * 126) / 2-(T / 2) * \log |\Psi|-(1 / 2) \sum_{t=1}^{T}\left(\tilde{q}_{t}^{\prime} \Psi^{-1} \tilde{q}_{t}\right)$,

where $\Psi=A * \Sigma^{*} A^{\prime}$. From Greene (1990, p. 517-18), one can rewrite the $\log$ likelihood function (A.2) as

(A.3) $\log \mathrm{L}=-(\mathrm{T} * 126) / 2-(\mathrm{T} / 2) * \log |\Psi|-(\mathrm{T} / 2) * \operatorname{tr}\left(\Psi^{-1} \mathrm{~S}\right)$, where $\operatorname{tr}$ denotes trace, and where

$$
S=(1 / T) \sum_{t=1}^{T} \tilde{q}_{t} * \tilde{q}_{t}^{\prime}
$$

is the moment matrix of the data. From Greene (1990, p. 518), one can show that

$$
\text { (A.5) } \quad \partial(\log \mathrm{L}) / \mathrm{d} \Psi \equiv \mathrm{B}=-(\mathrm{T} / 2) *\left[\Psi^{-1}-\Psi^{-1} * \mathrm{~S}^{*} \Psi^{-1}\right] .
$$

Furthermore, one can show that

$$
\partial \Psi / \mathrm{d} \beta_{1} \equiv C_{1}=A * \Sigma * \mathrm{COST}^{\prime}+\operatorname{cosT} * \Sigma * A^{\prime} .
$$

It thus follows that the gradient of $\log (L)$ with respect to $\beta_{1}$ is

$$
\partial(\log L) / d \beta_{1}=\operatorname{tr}\left(B * C_{1}^{\prime}\right)
$$

in other words, the effect of $\beta_{1}$ on the $\log$ likelihood is equal to 
the effect of $\beta_{1}$ on the $[1,1]$ element of $\Psi$ times the effect of the [1,1] element of $\Psi$ on $\log (L)$, plus the effect of $\beta_{1}$ on the $[1,2]$ element of $\Psi$ times the effect of the $[1,2]$ element of $\Psi$ on $\log (L)$, and so on. One can similarly compute the gradient of $\log (L)$ with respect to $\beta_{2}$ through $\beta_{4}$.

Next, for the covariance matrix $\Sigma$, one can show that

(A. 8)

$$
\partial \Psi / \mathrm{d} \Sigma_{\mathrm{i} i} \equiv \mathrm{D}_{\mathrm{i}}=\mathrm{A}[\ldots, \mathrm{i}] * \mathrm{~A}[\ldots, \mathrm{i}]^{\prime},
$$

where $A[., i]$ is the ith column of A. Combining (A.5) and (A.8), one can show that the gradient of the log likelihood with respect to the the element $[i, i]$ of the diagonal matrix $\Sigma$ is given by

$$
\partial(\log L) / d \Sigma_{i i}=\operatorname{tr}\left(B * D_{i}^{\prime}\right)
$$

Data Description

I estimate the model using annual data on 126 disaggregated manufacturing industries. These industries cover the entire manufacturing sector, and generally correspond to the three-digit Standard Industrial Classification; in some cases, I combine two or more industries to conform to available input-output data. A complete list of sample industries can be found at the end of this appendix.

I use three measures of industry activity: the growth rate of employment; the growth rate of gross output, defined as real shipments plus the change in real inventories; and the growth rate of real value added. Following Basu and Fernald (1993), I measure value added growth as the Tornquist approximation to a divisia index; real value added growth between $t-1$ and $t$ is thus
(A. 10)
$1 / \mathrm{SVA} * \mathrm{GOUT}_{t}-(1-\mathrm{SVA}) / \mathrm{SVA} * \mathrm{GMAT}_{t}$,

where GOUT equals the growth rate of gross output, GMAT equals the 
growth rate of materials, and SVA is the average share of nominal value added in nominal gross output over $t-1$ and $t$.

All three measures of $q_{t}$ are constructed by aggregating annual four-digit data from the Penn-SRI-Census Productivity Database (described in Bartlesman, Caballero and Lyons (1994)) to the three-digit level. Real output and real materials are expressed in 1972 dollars. The data cover the period 1958-1986; after converting to growth rates and measuring inventory change, the employment measure runs from 1959-1986 while the output and value added measures run from 1960-1986. These are the sample periods for subsequent estimation.

Equation (5) in Model One expresses output fluctuations as a function of taste shocks, technology shocks, and elements of the matrices COST and DEM. In terms of model parameters, these matrices in turn satisfy

$$
\cos T=\left[(I D-\beta)^{-1}\right]^{\prime}
$$

and

$$
D E M_{i k}=\operatorname{CosT}_{k i} a_{k} /\left(\sum_{z=1}^{N} \operatorname{CosT} z a_{z}\right),
$$

where ID is an $N$-by- $N$ identity matrix; $\beta$ is an $N$-by- $N$ matrix whose [k, i] element equals $\beta_{k i}$; and $a_{k}$ is the steady-state share of good $k$ in overall consumption.

I construct the matrices COST and DEM using data from the 1977 detailed US input-output study. To begin, I construct a 158-by-158 matrix $\beta$, whose $[k, i]$ element equals the share of industry i's cost directly attributable to good $k$. I construct $\beta$ from raw input-output data using methods described in Shea (1991 and 1993); in terms of terminology introduced in these papers, $\beta_{k i}$ is the Direct Cost Share of $k$ in $i$. As in this previous work, $\beta_{k i}$ includes both i's purchases of $k$ as a material 
input and an imputed service flow from i's use of $k$ as capital. The 158 industries consist of the 126 sample manufacturing industries, plus 32 nonmanufacturing industries listed below. Next, following (A.11), I construct a 158-by-158 "total requirements" matrix TOTAL by computing the transpose of the Leontief inverse of $\beta$. I then construct COST by taking the rows and columns of TOTAL corresponding to the 126 sample industries. Given COST, I construct DEM following (A.12). I define industry $k$ 's final demand $a_{k}$ as the sum of purchases from consumption, government, and the 32 nonmanufacturing industries.

Following Model Two, I construct the matrix SIZE using the Penn-Census-SRI database described above. I define industry size as the industry's share of nominal value added in manufacturing in year $t$, averaged over the period 1959-1986.

Following Model Three, I construct the matrix CITY using County Business Patterns (CBP) data from the Department of Commerce. The CBP provides employment by disaggregated industry for every county in the United States. I aggregate counties into the 273 standard metropolitan statistical areas (SMSAs) defined by the 1980 Census of Population. While CBP data is available annually since 1958, I use 1977 data only; this is reasonable provided the spatial distribution of industries is stable over time. To preserve confidentiality, employment in county-industries with a small number of establishments is reported in the CBP as a range (e.g. 100-250; 250-499); in these cases, I take midpoints. I construct the elements of CITY following (18), where SHARE1 $j i$ is defined as the share of industry i's total 1977 employment in the 273 SMSAs accounted for by SMSA $j$, while SHARE $_{k j}$ is defined as the share of SMSA j's total manufacturing employment in 1977 accounted for by industry $k$. 
Finally, I construct the vector SHARE for employment as the mean over 1958-1986 of annual industry shares of manufacturing employment; for value added, SHARE is the mean over 1959-1986 of annual industry shares of double deflated real value added in 1972 dollars; for gross output, SHARE is the mean over 1959-86 of annual industry shares of real gross output in 1972 dollars.

Manufacturing Industries Used In Estimation:

1. SIC 201: Meat Products

2. SIC 202: Dairy Products

3. SIC 203: Prepared Foods

4. SIC 204: Grain Mill Products

5. SIC 205: Baked Goods

6. SIC 206: Confectionary

7. SIC 207: Fats and Oils

8. SIC 208: Beverages

9. SIC 209: Miscellaneous Food

10. SIC 21: Tobacco Products

11. SIC 221-223 and 226: Broadwoven Fabrics

12. SIC 224: Narrow Fabrics

13. SIC 225: Knit Goods

14. SIC 227: Floor Coverings

15. SIC 228: Yarn and Thread

16. SIC 229: Miscellaneous Textiles

17. SIC 231-238: Clothing

18. SIC 239: Miscellaneous Apparel

19. SIC 241: Logging

20. SIC 242: Sawmills

21. SIC 243: Millwork and Plywood

22. SIC 244: Wood Containers

23. SIC 245: Manufactured Homes

24. SIC 249: Miscellaneous Wood

25. SIC 251: Household Furniture

26. SIC 252: Office Furniture

27. SIC 253: Public Building Furniture

28. SIC 254: Partitions

29. SIC 259: Miscellaneous Furniture

30. SIC 261: Pulp Mills

31. SIC 262: Paper Mills

32. SIC 263: Paperboard Mills

33. SIC 264: Converted Paper Products

34. SIC 265: Paperboard Boxes

35. SIC 266: Building Paper and Board

36. SIC 271: Newspapers

37. SIC 272: Periodicals

38. SIC 273: Books

39. SIC 274: Miscellaneous Publishing

40. SIC 275: Commercial Printing 


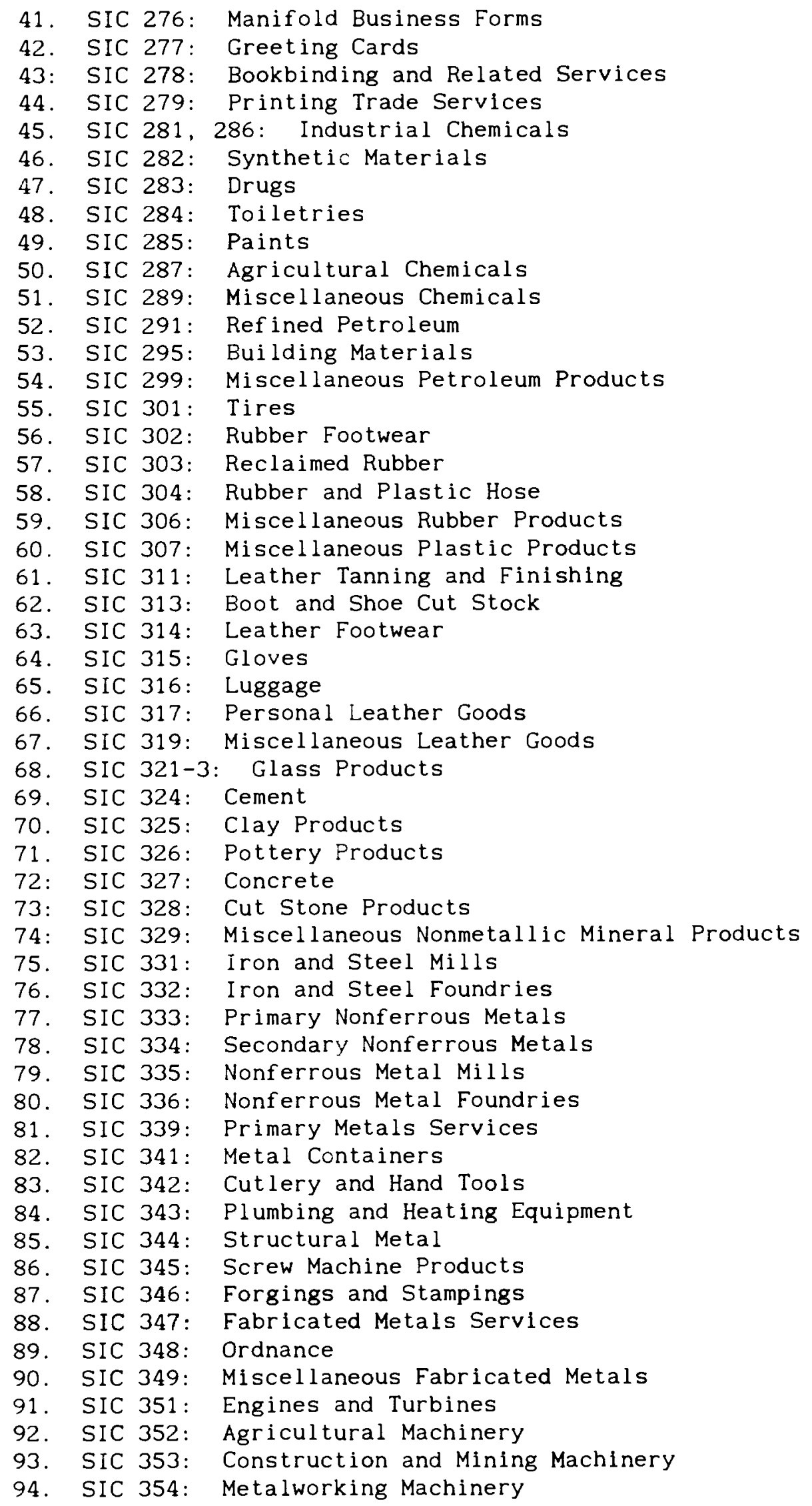




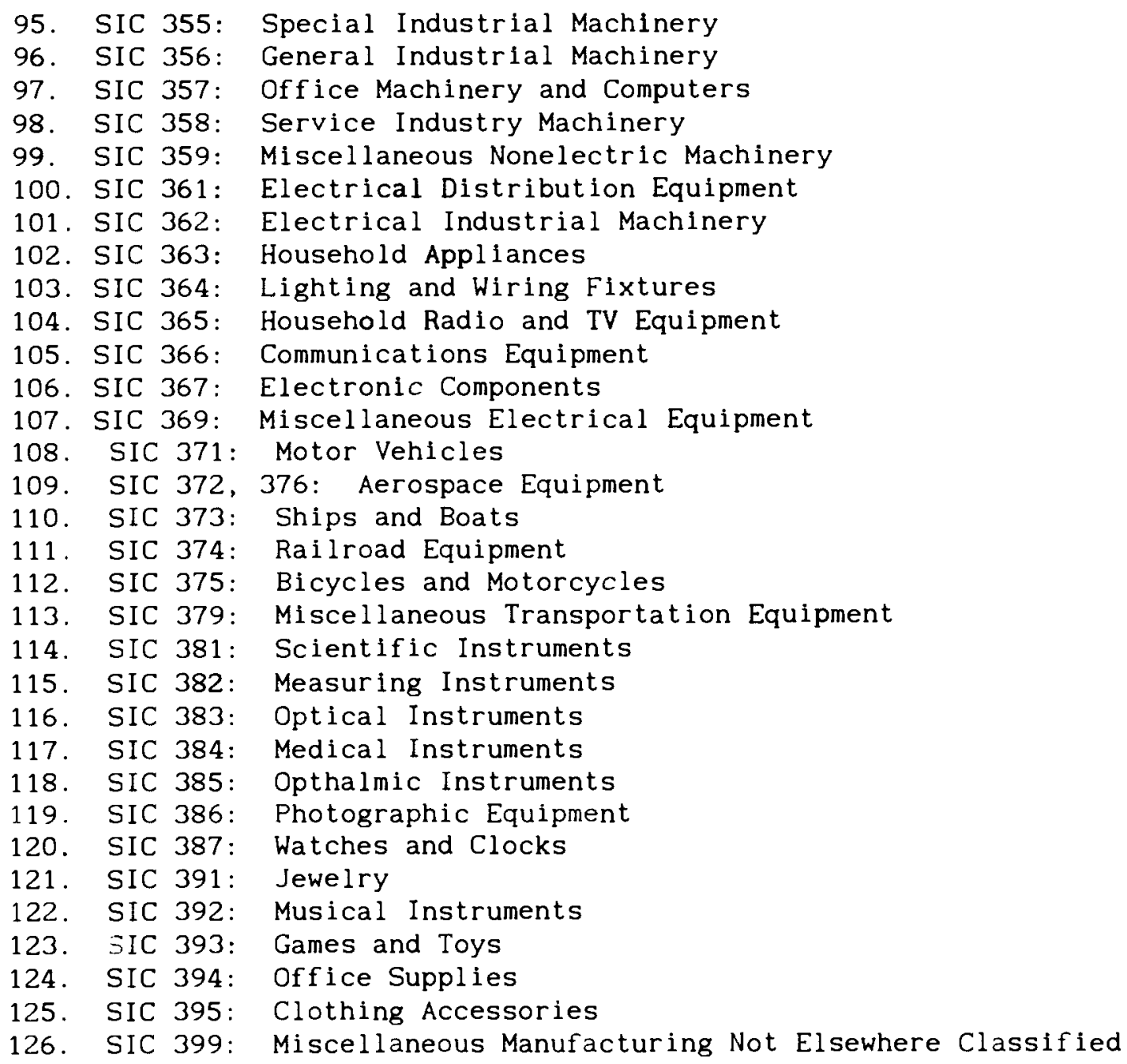


146. SIC 60-66: Finance, Insurance, Real Estate

147. SIC 70: Hotels

148. SIC 72: Personal Services

149: SIC 73: Business Services

150: SIC 75: Automotive Services

151: SIC 76: Repair Services

152: SIC 78-79: Amusements

153: SIC 80: Health Care

154: SIC 81, 89: Legal and Professional Services

155: SIC 82: Education

156: SIC 83: Social Services

157: SIC 84, 86: Membership Organizations

158: Various SIC: Government Enterprise 


\section{REFERENCES}

Bartlesman, Eric; Caballero, Ricardo; and Richard Lyons (1994), "Customer and Supplier-Driven Externalities," American Economic Review 84 (4), 1075-1084.

Basu, Susanto, and John Fernald (1993), "Are Apparent Productive Spillovers a Figment of Specification Error?", mimeo.

Baxter, Marianne, and Robert King (1991), "Productive Externalities and Business Cycles," Federal Reserve Bank of Minneapolis Institute for Empirical Macroeconomics Discussion Paper 53, November.

Cooper, Russell, and John Haltiwnager (1990), "Inventories and the Propogation of Sectoral Shocks," American Economic Review 80, $170-190$

Cooper, Russell, and John Haltiwanger (1993), "Empirical Evidence on Macroeconomic Complementarities," forthcoming Review of Economics and Statistics.

Cooper, Russell, and Andrew John (1988), "Coordinating Coordination Failures in Keynesian Models," Quarterly Journal of Economics 103, $441-463$

Diamond, Peter (1982), "Aggregate Demand Management in Search Equilibrium," Journal of Political Economy 90, 881-894. 
Friedman, Benjamin, and Kenneth Kuttner (1992), "Money, Income, Prices, and Interest Rates," American Economic Review 82, 472-492.

Greene, William (1990), Econometric Analysis, New York: MacMillan.

Long, John, and Charles Plosser (1983), "Real Business Cycles," Journal of Political Economy $91,39-69$.

Long, John, and Charles Plosser (1987), "Sectoral Versus Aggregate Shocks," American Economic Review 77, 333-336.

Marshall, Alfred (1949), Principles of Economics, eighth edition, New York: The MacMillan Company.

Miller, Ronald (1992), "Growth, Transition and the International Comparison of Persistence in Income Innovations," mimeo.

Murphy, Kevin; Shleifer, Andrei; and Robert Vishny (1989 a), "Building Blocks of Market Clearing Business Cycle Models," NBER Macroeconomics Annual, ed. Olivier Blanchard and Stanley Fischer, $247-301$.

Murphy, Kevin; Shleifer, Andrei; and Robert Vishny (1989 b), "Industrialization and the Big Push," Journal of Political Economy $97,1003-1026$. 
Norrbin, Steffan, and Don Schlagenhauf (1990), "Sources of Output Fluctuations in the United States During the Inter-War and Post-War Years," Journal of Economic Dynamics and Control 14 (1990), 523-551

Neumann, George, and Robert Topel (1991), "Employment Risk, Diversification, and Unemployment," Quarterly Journal of Economics $105,1341-1365$.

Shea, John (1991), "The Input-Output Approach to Demand-Shift Instrumental Variable Selection: Technical Appendix," University of Wisconsin Social Systems Research Institute Working Paper 9115.

Shea, John (1993), "The Input-Output Approach to Instrument Selection," Journal of Business and Economic Statistics 11, 145-155.

Shea, John (1995), "Comovement in Cities," Carnegie-Rochester Conference on Public Policy, forthcoming. 


\section{FOOTNOTES}

${ }^{1}$ Cooper and John (1988) use the phrase "strategic complementarity" to refer to linkages that inherently depend on market imperfections.

2Miller (1992) adopts a similar strategy in a different context; he tests whether international activity spillovers are an important source of endogenous growth by examining whether large countries have more persistent income innovations than small countries, exploiting the fact that transitory shocks to large countries should have more impact on international activity than transitory shocks to small countries.

3 Notice that even if aggregate activity spillovers are present, industry size will be an economically important determinant of comovement variation across industry pairs only to the extent that the available data classification system divides economic activity into meaningful aggregates. Suppose, for instance, that the underlying economy consists of a large number of equally-sized independent sectors, and that the data authority arbitrarily groups these sectors into industries of varying size. Then a given-sized shock to a "large" industry will still propagate more strongly than a similar-sized shock to a "small" industry; however, the large industry will have a smaller standard deviation of shocks than the smaller industry, since the large industry's shock will be the average over a larger number of uncorrelated shocks.

\footnotetext{
Marshall (1949, p.273) writes: "A district which is dependent chiefly on one industry is liable to extreme depression, in case of a
} 
falling-off in the demand for its produce, or of a failure in the supply of the raw material which it uses. This evil again is in a great measure avoided by those large towns... in which several distinct industries are strongly developed. If one of them fails for a time, the others are likely to support it indirectly..." Neumann and Topel (1991) find that cities with a poorly diversified employment base indeed have higher average rates of unemployment than cities with a well-diversified base.

${ }^{5}$ also experimented with measuring SIZE using the period average shares of employment, real gross output, and real value added. Estimates of $\beta_{1}$ and $\beta_{2}$ (cost and demand linkages) were not sensitive to the choice of SIZE. Using employment shares tended to raise the estimates of $\beta_{3}$ (aggregate spillovers), to the point of statistical significance in some cases, and reduce the estimates of $\beta_{4}$ (local spillovers), although local spillovers were still statistically significant. Using real gross output or real value added shares tended to make estimates of $\beta_{3}$ negative, and tended to increase the estimates of $\beta_{4}$.

${ }^{6}$ Friedman and Kuttner (1992) and others have found the paper-bill spread to be a highly informative indicator of monetary policy, with more predictive power for aggregate output than other commonly used indicators such as $M 1$ or the $T-b i l l$ rate alone.

${ }^{7}$ For output, the average $R$-squared from these regressions is 0.34 . For employment and value added, the average R-squared is 0.30 and 0.31 .

${ }^{8}$ Notice that these industry-by-industry estimates of $\mu$ and $G$, while 
consistent, are not efficient due to the correlation of shocks across industries.

${ }^{9}$ For the fitted model including the effects of aggregate shocks, the sixth column reports the correlation between the pairwise correlations in the original data and the correlations implied by the fitted $\Psi$ matrix including $\hat{G} * \hat{\phi} * \hat{G}^{\prime}$. For the fitted model excluding aggregate shocks, the sixth column reports the correlation between the pairwise correlation in the data residuals and the correlations implied by the fitted $\Psi$ matrix excluding $\hat{G} * \hat{\phi} * \hat{G}^{\prime}$.

${ }^{10}$ Cooper and Haltiwanger (1993) survey evidence on complementarities.

${ }^{11}$ Norrbin and Schlagenhauf (1990) allow for lagged averages of other industries' outputs to affect current industry output. However, their weighting scheme is not based on any underlying theory of complementarities, and they do not allow for any contemporaneous propagation of shocks across sectors.

${ }^{12}$ In Shea (1995) I also attempt to put some structure on the concept of "local spillovers" by examining one of the most promising microeconomic foundations for local spillovers: limited intercity tradeability of certain goods due to high transpotration costs. Empirically, nontraded goods do not seem capable of explaining the phenomenon of local spillovers. 
TABLE 1

Comovement and Aggregate Volatility

$\operatorname{Var}(q) \cong \operatorname{SHARE}^{*} \Psi * \mathrm{SHARE}^{\prime}$

--------Standard Deviations--------

Off- $\quad \%$ Due To

Activity Measure Actual Implied Diagonal Diagonal Comovement

$\begin{array}{cccccc}\text { Employment } & 4.31 & 4.42 & 0.99 & 4.31 & 94.9 \\ \text { Gross Output } & 5.61 & 5.42 & 2.08 & 5.00 & 85.4 \\ \text { Value Added } & 7.37 & 6.67 & 2.99 & 5.97 & 80.0\end{array}$

NOTES: the second column presents the standard deviation of annual employment, gross output, and value added growth in US manufacturing over 1959-86 for employment and 1960-86 for output and value added. The third column presents the standard deviation implied by equation (2) in the text, where SHARE and $\Psi$ are constructed using 126 three-digit manufacturing industries. The fourth and fifth columns report the standard deviation implied by the diagonal and of $f$-diagonal elements of $\Psi$, while the sixth column reports the share of aggregate variance due to the off-diagonal "comovement" term. 
TABLE 2

Empirical Estimates

$$
\begin{gathered}
q_{t}=\mu+G * a_{t}+A * v_{t} \\
A=I D+\beta_{1} \operatorname{COST}+\beta_{2} D E M+\beta_{3} \text { SIZE }+\beta_{4} \text { CITY } \\
\operatorname{Var}\left(v_{t}\right)=\Sigma
\end{gathered}
$$

Activity Measure $\quad \beta_{1} \quad \beta_{2} \quad \beta_{3} \quad \beta_{4}$

$\begin{array}{ccccc}\text { Employment } & 0.325 & 0.857 & 0.385 & 1.451 \\ & * *(0.104) & *(0.103) & (0.401) & * *(0.282) \\ \text { Gross Output } & 0.402 & 1.029 & 0.043 & 1.274 \\ & * *(0.090) & * *(0.101) & (0.358) & * *(0.273) \\ \text { Value Added } & 0.304 & 0.242 & 0.655 & 1.582 \\ & * *(0.055) & * *(0.090) & (0.487) & * *(0.295)\end{array}$

NOTES: this table presents maximum likelihood estimates of the $\beta$ parameters. Standard errors are in parentheses and are estimated by numerical computation of the Hessian matrix at the maximum likelihood estimates. A (**) denotes significance at 5 percent. See text for further details. 
TABLE 3

Goodness of Fit

\begin{tabular}{|c|c|c|c|c|c|}
\hline \multirow{2}{*}{$\begin{array}{l}\text { Activity } \\
\text { Measure }\end{array}$} & \multirow[b]{2}{*}{ Case } & \multirow{2}{*}{$\begin{array}{c}\text { Implied } \\
\text { Volatility } \\
\end{array}$} & \multicolumn{3}{|c|}{-Pairwise Correlations- } \\
\hline & & & Mean & Stan Dev & Corr \\
\hline \multirow[t]{4}{*}{ Employment } & Data & 4.42 & 0.341 & 0.423 & 1 \\
\hline & $\begin{array}{l}\text { Fitted, including } \\
\text { aggregate shocks }\end{array}$ & 4.32 & 0.305 & 0.353 & 0.782 \\
\hline & Residuals & 3.09 & 0.254 & 0.350 & 1 \\
\hline & $\begin{array}{l}\text { Fitted, excluding } \\
\text { aggregate shocks }\end{array}$ & 2.95 & 0.198 & 0.226 & 0.286 \\
\hline \multirow[t]{4}{*}{ Output } & Data & 5.42 & 0.284 & 0.394 & 1 \\
\hline & $\begin{array}{c}\text { Fitted, including } \\
\text { aggregate shocks }\end{array}$ & 5.83 & 0.280 & 0.338 & 0.779 \\
\hline & Residuals & 3.70 & 0.185 & 0.316 & 1 \\
\hline & $\begin{array}{l}\text { Fitted, excluding } \\
\text { aggregate shocks }\end{array}$ & 4.33 & 0.177 & 0.207 & 0.386 \\
\hline \multirow[t]{4}{*}{ Value Added } & Data & 6.67 & 0.228 & 0.364 & 1 \\
\hline & $\begin{array}{l}\text { Fitted, including } \\
\text { aggregate shocks }\end{array}$ & 7.81 & 0.263 & 0.323 & 0.782 \\
\hline & Residuals & 4.45 & 0.142 & 0.292 & 1 \\
\hline & $\begin{array}{l}\text { Fitted, excluding } \\
\text { aggregate shocks }\end{array}$ & 6.08 & 0.194 & 0.219 & 0.358 \\
\hline \multicolumn{6}{|c|}{$\begin{array}{l}\text { NOTES: This table presents goodness-of-fit statistics for the fitted } \\
\text { model. For each activity measure, the column "Implied Volatility" } \\
\text { presents the standard deviation of aggregate manufacturing activity } \\
\text { implied by the formula Var(q) = SHARE' } \Psi \text { "SHARE, setting } \Psi \text { either to } \\
\text { the observed covariance matrix of the original data, the covariance matrix } \\
\text { of the residuals from projecting the data on aggregate shocks, or to } \\
\text { fitted } \Psi \text { including or exluding the effects of aggregate shocks. The } \\
\text { remaining three columns present statistics for the pairwise correlations } \\
\text { implied by each case. See the text for further discussion. }\end{array}$} \\
\hline
\end{tabular}


TABLE 4

Variance Decomposition

\begin{tabular}{|c|c|c|c|}
\hline $\begin{array}{l}\text { Activity } \\
\text { Measure }\end{array}$ & Component & $\begin{array}{c}\text { Impact } \\
\hat{G} \\
\end{array}$ & $\begin{array}{c}\text { Shock } \\
\hat{F}\end{array}$ \\
\hline \multirow[t]{7}{*}{ Employment } & Agg Shocks & 53.4 & 4.6 \\
\hline & Diagonals & 3.5 & 3.5 \\
\hline & $\operatorname{cosT}$ & 2.5 & 6.9 \\
\hline & DEM & 6.5 & 10.1 \\
\hline & SIZE & 3.3 & 6.8 \\
\hline & CITY & 15.1 & 35.9 \\
\hline & Interactions & 15.7 & 32.1 \\
\hline \multirow[t]{7}{*}{ Gross Output } & Agg Shocks & 44.8 & 3.7 \\
\hline & Diagonals & 10.9 & 10.9 \\
\hline & COST & 5.3 & 12.1 \\
\hline & DEM & 10.6 & 13.4 \\
\hline & SIZE & 0.5 & 0.9 \\
\hline & CITY & 16.4 & 34.5 \\
\hline & Interactions & 11.5 & 24.5 \\
\hline \multirow[t]{7}{*}{ Value Added } & Agg Shocks & 39.3 & 2.9 \\
\hline & Diagonals & 13.2 & 13.2 \\
\hline & $\operatorname{COST}$ & 4.0 & 7.1 \\
\hline & DEM & 1.9 & 2.3 \\
\hline & SIZE & 8.1 & 13.0 \\
\hline & CITY & 18.6 & 34.3 \\
\hline & Interactions & 14.8 & 27.1 \\
\hline
\end{tabular}

NOTES: This table presents the decomposition of the variance implied by the fitted model into components attributable to aggregate shocks, shock variances, individual complementaritles, and interactions among complementarities. The third column reports results using the OLS estimates from regressing activity on OIL and SPREAD to measure the impact of aggregate shocks. The fourth column reports results using the estimated direct effects matrix $F$ to measure the impact of aggregate shocks. See the text for further information. 